\title{
Combined effects of sodium carbonate pretreatment and hybrid drying methods on the nutritional and antioxidant properties of dried Goji berries
}

\section{Song, H. H.; Bi, J. F. *; Chen, Q. Q. *; Zhou, M.; Wu, X. Y.; Song, J. X.}

Institute of Food Science and Technology, Chinese Academy of Agricultural Science (CAAS)/ Key Laboratory of Agro-Products Processing, Ministry of Agriculture, Beijing, China

*E-mail of the corresponding author: bjfcaas@126.com (Bi J. F.); celerylc@163.com (Chen Q. Q.)

\begin{abstract}
Combined effects of sodium carbonate (SC) pretreatment and hybrid drying methods (freeze drying-instant controlled pressure drop drying (FD-ICPDD), hot air drying (HAD-ICPDD) on nutritional and antioxidant properties of Goji berries were investigated. Compared with distilled water pretreatment, SC pretreatment could obtain products with better quality. Goji dried by FDICPDD showed better overall quality than that dried by HAD or FD alone. FD-ICPDD products exhibited higher contents of total Lycium barbarum polysaccharide $(140 \mathrm{~g} / \mathrm{kg})$, total carotenoids $(2.4 \mathrm{~g} / \mathrm{kg})$ as well as the strongest $\mathrm{ABTS} .^{+}$radical scavenging activity (57.6 $\mu \mathrm{mol} \mathrm{TE} / \mathrm{g}$ ). FD-ICPDD could be an alternative drying method for processing valuable agro-products.
\end{abstract}

Keywords: sodium carbonate, instant controlled pressure drop drying, nutritional properties, antioxidant activity 


\section{Introduction}

Goji is in the Solanaceae family that has been used as a functional food and traditional herb in Asian countries ${ }^{[1]}$. It contains many active compounds including phenols, carotenoids and polysaccharides possessing biological activates such as anti-aging, antioxidant properties and so on ${ }^{[2]}$. For preservation, drying is still the main processing method to prolong the shelf-life of Goji ${ }^{[3]}$. Several drying methods, such as sun drying, hot air drying, vacuum drying, and freeze drying, have been conducted on Goji ${ }^{[4,5]}$. Each drying technique has advantages and restrictions. However, combined drying process can integrate the strengths of different drying methods so as to preserve quality of final products ${ }^{[6]}$. Instant controlled pressure drop drying (ICPDD), also called explosion puffing drying (EPD) ${ }^{[7]}$, is an emerging drying technology which always in conjunction with other drying methods like hot air and freeze drying and produce the products with better quality ${ }^{[8]}$. Drying of fresh Goji is difficult owing to the wax layer on the surface which could block moisture transport. Sodium carbonate (SC) was used as a traditional pretreatment to break the wax layer of Goji so as to accelerate the drying rate. But there is little report about the effect of SC pretreatment coupled with combined drying especially on ICPDD of Goji. Hence, to enhance drying efficiency and improve the overall quality, combined effects of sodium carbonate pretreatment and hybrid drying methods (FD-ICPDD and HAD-ICPDD) on the nutritional and antioxidant properties of Goji was evaluated. Freeze drying and hot air drying were used as comparative study.

\section{Materials and Methods}

\subsection{Sample preparation}

\subsubsection{Raw material}

Goji was grown in Yinchuan, Ningxia Hui Autonomous Region, China with initial water content was about $804 \pm 2 \mathrm{~g} / \mathrm{kg}$ dry base (d.b.). Those without mechanical damage and decay were used and the fruit pedicles were removed before experiment.

\subsubsection{Pretreatment}

Goji fruits were immersed into the SC solution (20 g/kg) for $1 \mathrm{~min}$ at room temperature with the liquid to solid ratio of 10:1 (ml:g). Control samples were treated by distilled water (DW) under the same condition. Fresh Goji fruits were used for HAD and HAD-ICPDD. For FD and FD-ICPDD processing, samples were frozen at $-80^{\circ} \mathrm{C}$ before used. 


\subsubsection{Equipment and Drying Process}

Freeze dryer (Alphal 1-4Lplus, MARIN CHRIST Co. Ltd Osterode, Germany), hot air dryer (HDS-D120B-D, Haiti Sheng Machinery Co. Ltd., Liaoning, China) and instant controlled pressure drop dryer (Tianjin Qin-de New Material Technology Co. Ltd., Tianjin, China) were used. The drying conditions of four different drying methods are exhibited in

Table 1. The dried products were ground into powder and pass through a 60 mesh sieve, which were then kept at $4^{\circ} \mathrm{C}$ for further chemical analysis.

Table 1. Drying conditions of four different drying methods

\begin{tabular}{|c|c|c|c|}
\hline $\begin{array}{l}\text { Drying } \\
\text { Methods }^{\mathrm{a}}\end{array}$ & $\begin{array}{l}\text { Pretreat } \\
\text { ments }^{\text {a }}\end{array}$ & Drying Conditions & $\begin{array}{l}\text { Drying } \\
\text { Time(h) }\end{array}$ \\
\hline Freeze drying & DW & $\begin{array}{l}\text { First drying stage: at }-55^{\circ} \mathrm{C} \text { and } 0.37 \mathrm{kPa} \text {; } \\
\text { Second drying stage: at } 25^{\circ} \mathrm{C}\end{array}$ & $58 \mathrm{~h}$ \\
\hline \multirow{3}{*}{$\begin{array}{l}\text { Freeze drying } \\
\text {-instant } \\
\text { controlled } \\
\text { pressure drop } \\
\text { drying }\end{array}$} & SC & The drying conditions was the same as DW & $58 \mathrm{~h}$ \\
\hline & DW & $\begin{array}{l}\text { Freeze drying at }-55^{\circ} \mathrm{C} \text { and } 0.37 \mathrm{kPa} \text { for } 14 \mathrm{~h} \text {; } \\
\text { explosion puffing of } 90^{\circ} \mathrm{C} \text { for } 15 \mathrm{~min} \text {, then } \\
\text { vacuum drying at }-0.1 \mathrm{MPa} \text { and } 60^{\circ} \mathrm{C} \text { for } 1.5 \mathrm{~h} \text {. }\end{array}$ & $15.5 \mathrm{~h}$ \\
\hline & SC & The drying conditions was the same as DW & $15.5 \mathrm{~h}$ \\
\hline \multirow{2}{*}{ Hot air drying } & DW & $\begin{array}{l}\text { The drying time and temperature of air drying } \\
\text { was } 40^{\circ} \mathrm{C}(2 \mathrm{~h})-50^{\circ} \mathrm{C}(4 \mathrm{~h})-60^{\circ} \mathrm{C}(12 \mathrm{~h}) \text {, air } \\
\text { velocity } 1.2 \mathrm{~m} / \mathrm{s} \text {, relative humidity } 40 \%\end{array}$ & $18 \mathrm{~h}$ \\
\hline & SC & $\begin{array}{l}\text { The drying time and temperature of air drying } \\
\text { was } 40^{\circ} \mathrm{C}(2 \mathrm{~h})-50^{\circ} \mathrm{C}(4 \mathrm{~h})-60^{\circ} \mathrm{C}(8 \mathrm{~h}) \text {, air } \\
\text { velocity } 1.2 \mathrm{~m} / \mathrm{s} \text {, relative humidity } 40 \%\end{array}$ & $14 \mathrm{~h}$ \\
\hline $\begin{array}{l}\text { Hot air - } \\
\text { instant }\end{array}$ & DW & $\begin{array}{l}\text { Hot air drying: } 40^{\circ} \mathrm{C}(2 \mathrm{~h})-50^{\circ} \mathrm{C}(4 \mathrm{~h}) \text {; explosion } \\
\text { puffing at } 90^{\circ} \mathrm{C} \text { for } 15 \mathrm{~min} \text {, then vacuum drying } \\
\text { at }-0.1 \mathrm{MPa} \text { and } 60^{\circ} \mathrm{C} \text { for } 1.5 \mathrm{~h} \text {. }\end{array}$ & $7.5 \mathrm{~h}$ \\
\hline $\begin{array}{l}\text { pressure drop } \\
\text { drying }\end{array}$ & SC & $\begin{array}{l}\text { Hot air drying: } 40^{\circ} \mathrm{C}(2 \mathrm{~h})-50^{\circ} \mathrm{C}(2.5 \mathrm{~h}) \text {; } \\
\text { explosion puffing at } 90^{\circ} \mathrm{C} \text { for } 15 \mathrm{~min} \text {, then } \\
\text { vacuum drying at }-0.1 \mathrm{MPa} \text { and } 60^{\circ} \mathrm{C} \text { for } 1.5 \mathrm{~h}\end{array}$ & $6 \mathrm{~h}$ \\
\hline
\end{tabular}

\subsection{Sample extraction}

Methanol-water solution was applied for sample extraction in this study. The extraction method was the same as Istrati et al. (2013) ${ }^{[9]}$. Samples were then filtered pass through a $0.45 \mu \mathrm{m}$ microporous membrane for the analysis of total phenolic content, total flavonoid content, and antioxidant activity on the UV-visible spectrophotometer (UV1800, Shimadzu Co. Ltd., Kyoto, Japan). 


\subsection{Nutritional properties}

\subsubsection{Total carotenoids content}

Total carotenoids content (TCC) was measured according to Knockaert et al. (2012) ${ }^{[10]}$..

\subsubsection{Total Lycium barbarum Polysaccharide content}

The total Lycium barbarum polysaccharide (LBP) content was performed according to the procedure presented by Zhao et al. (2015) ${ }^{[4]}$ with slight modification. Goji powder was extracted by ultrasonic at $40 \mathrm{kHz}$ for $2 \mathrm{~h}$. After centrifugated, the supernatant was condensed to a proper volume and precipitation was dissolved with ethanol until the concentration of ethanol is over $80 \%$. Then the solution was placed at $4^{\circ} \mathrm{C}$ for $24 \mathrm{~h}$ to make the LBP settled. The settling was dissolved with distilled water and set to $100 \mathrm{~mL}$. Solutions were analyzed for LBP, by the phenol-sulfuric acid method and concentrations determined against a glucose standard.

\subsubsection{Total phenolic content}

Briefly, $0.4 \mathrm{~mL}$ of the extracts was transferred to the volumetric flask $(10 \mathrm{~mL})$ followed by $1 \mathrm{~mL}$ of Folin-Ciocalteu's reagent (10 times dilution) and after $6 \mathrm{~min} 2 \mathrm{~mL}$ of sodium carbonate solution $(75 \mathrm{~g} / \mathrm{kg})$ was added. Then the volumetric flask was adjusted to the total volume with the distilled water and mixed thoroughly. The mixture was allowed to stand for $60 \mathrm{~min}$ at $30^{\circ} \mathrm{C}$ and measured at $765 \mathrm{~nm}{ }^{[11]}$. The TPC was presented as $\mathrm{mg} / \mathrm{g}$ dry base (d.b.) of gallic acid equivalents (GAE).

\subsection{Antioxidant activity (FRAP and ABTS assay) measurement}

The FRAP and ABTS assay were measured according to the method of Wang et al. (2012) ${ }^{[13]}$ and Jihyun et al. (2010) ${ }^{[14]}$, respectively.

\subsection{Statistical Analysis}

All the experimental data was conducted in three replicates and the results were expressed as mean \pm standard deviation. The SPSS V21.0 Software (IBM Corporation, Chicago, USA) was used for statistical analysis, applying a one-way analysis of ANOVA test and Duncan's multiple comparison test at $P<0.05$.

\section{Materials and Methods}

\subsection{Total carotenoids content}

The reddish-orange color of Goji fruits comes from a group of carotenoids, which can be easily oxidized by heat, light, and high oxygen tension ${ }^{[15]}$. The TCC for fresh Goji was 3.6 $\mathrm{g} / \mathrm{kg}$ extract and the values of dried Goji was shown in Table 2. DW-fruits exhibited lower 
TCC values than SC-ones and the lowest TCC (1.6 g/kg) was obtained in HAD (DW) samples, owning to the effect of coexistence of high temperature, oxygen and longer drying time. The highest retention of TCC (71.4\%) was observed in FD (SC) samples, possibly because of the lower temperature and vacuum conditions during FD dehydration [16]. Similarly, less losses of TCC (36\%) in FD-ICPDD (DW) sample than that of HAD-ICPDD (DW) (43\%) ones.

Table 2 Dfferent drying methods and pretreatments on nutritional components and antioxidant activities of Lycium Barbarum

\begin{tabular}{cccccc}
\hline Treatments & $\begin{array}{c}\text { TCC } \\
(\mathbf{g} / \mathbf{k g})\end{array}$ & $\begin{array}{c}\text { LBP } \\
(\mathbf{g} / \mathbf{k g})\end{array}$ & $\begin{array}{c}\text { TPC } \\
(\mathbf{m g} \\
\text { GAE/g })\end{array}$ & $\begin{array}{c}\text { FRAP } \\
(\boldsymbol{\mu m o l} \\
\text { TE/g })\end{array}$ & $\begin{array}{c}\text { ABTS } \\
(\boldsymbol{\mu m o l} \\
\text { TE/g })\end{array}$ \\
\hline Fresh & $3.6 \pm 0.1 \mathrm{a}$ & $169 \pm 6 \mathrm{a}$ & $6.7 \pm 0.1 \mathrm{e}$ & $24.5 \pm 1.0 \mathrm{f}$ & $28.1 \pm 1.3 \mathrm{~g}$ \\
FD(DW) & $2.5 \pm 0.0 \mathrm{c}$ & $105 \pm 7 \mathrm{c}$ & $8.1 \pm 0.5 \mathrm{~d}$ & $29.7 \pm 2.7 \mathrm{e}$ & $50.1 \pm 1.3 \mathrm{c}$ \\
FD(SC) & $2.6 \pm 0.1 \mathrm{~b}$ & $107 \pm 1 \mathrm{c}$ & $8.4 \pm 0.1 \mathrm{~d}$ & $30.2 \pm 2.4 \mathrm{e}$ & $51.8 \pm 0.9 \mathrm{bc}$ \\
FD- & $2.3 \pm 0.1 \mathrm{~d}$ & $135 \pm 9 \mathrm{~b}$ & $10.5 \pm 0.1 \mathrm{bc}$ & $39.1 \pm 2.0 \mathrm{bc}$ & $53.3 \pm 0.8 \mathrm{~b}$ \\
ICPDD(DW) & $2.4 \pm 0.0 \mathrm{~cd}$ & $140 \pm 0 \mathrm{~b}$ & $11.3 \pm 0.3 \mathrm{a}$ & $43.7 \pm 1.0 \mathrm{a}$ & $57.6 \pm 0.5 \mathrm{a}$ \\
FD-ICPDD(SC) & & & & & \\
HAD(DW) & $1.6 \pm 0.1 \mathrm{~g}$ & $90 \pm 3 \mathrm{~d}$ & $8.1 \pm 0.3 \mathrm{~d}$ & $34.3 \pm 1.2 \mathrm{~d}$ & $40.0 \pm 2.3 \mathrm{f}$ \\
HAD(SC) & $1.7 \pm 0.1 \mathrm{f}$ & $91 \pm 5 \mathrm{~d}$ & $10.1 \pm 0.4 \mathrm{c}$ & $37.9 \pm 1.9 \mathrm{c}$ & $43.4 \pm 1.7 \mathrm{e}$ \\
HAD- & $2.1 \pm 0.1 \mathrm{e}$ & $95 \pm 1 \mathrm{~d}$ & $11.0 \pm 0.4 \mathrm{ab}$ & $40.9 \pm 2.5 \mathrm{abc}$ & $45.1 \pm 0.4 \mathrm{de}$ \\
ICPDD(DW) & & & & & \\
HAD- & $2.3 \pm 0.1 \mathrm{~d}$ & $110 \pm 1 \mathrm{c}$ & $11.4 \pm 0.3 \mathrm{a}$ & $41.7 \pm 1.7 \mathrm{ab}$ & $45.7 \pm 0.8 \mathrm{~d}$ \\
ICPDD(SC) & & & & & \\
\hline
\end{tabular}

Dates are expressed as dry base. Each value is expressed as mean value \pm SD (n $=3$ ). Different letters in the same column indicate significant differences at $p<0.05$, the same below. GAE: gallic acid equivalent; RE: rutin equivalent; TE: trolox equivalent

\subsection{Total LBP content}

LBP was one of the major active components in charge of biological activities of Goji ${ }^{\text {[17] }}$. There were significant distinctions of the LBP values between different drying processing. As shown in Table 2, the highest retention of LBP (82.9\%) was observed in the FD-ICPDD (SC) products, possibly because vacuum conditions of most of drying process. The LBP of FD-ICPD-dried Goji was higher than that of the HAD-ICPD-dried ones. The lowest content of LBP (90 g/kg) was found in HAD (DW) because of the longer drying time (12 h) at relatively higher drying temperature $\left(60^{\circ} \mathrm{C}\right)$. The content of LBP had no significant difference under the DW and SC pretreatments of the same drying method except the HAD-ICPDD. 


\subsection{Total phenolic content (TPC)}

The TPC of dried Goji was significantly influenced by the different pretreatments and drying methods ( $\mathrm{p}<0.05$ ). As shown in Table 2, TPC for the fresh samples was $6.7 \mathrm{mg}$ GAE/g, which was similar to that had been reported in the article ${ }^{[5]}$. The SC pretreatment exhibited higher TPC values than that of DW pretreatment in all the drying methods. For example, the TPC of FD-ICPDD dried samples with SC pretreatment were $7.8 \%$ higher than that of DW ones. The highest retention of TPC (11.4 mg GAE/g) was found in HADICPDD (SC) method, whereas the FD (DW) samples had the lowest value (8.1 mg GAE/g). It may be attributed to heat treatment that could liberate some phenolics and flavonoids which are mainly found in bound form in plant matrix ${ }^{[18]}$. On the other hand, the activity of polyphenol oxidase, which is responsible for oxidation of phenolics, tends to deactivation because of exposure to high temperature ${ }^{[19]}$. During thermal treatment, the liberation of phenolics might occur due to the decomposition of cellular components and covalent bonds ${ }^{[20]}$. Hence, the released phenolics tend to be more amenable for extraction. Chang et al. (2006) ${ }^{[21]}$ also found that the values of TPC and TFC of tomatoes had a significant increase compared to the fresh ones either through FD or HAD. The TPC content of FD-ICPDD (SC) were higher than that of the FD (SC) samples (25.3\%), which indicated that phenolics could be was liberated after ICPDD treatment.

\subsection{Antioxidant Activity}

Antioxidants like phenolic compounds could inhibit oxidation reaction by acting on hydrogen donors or free radical acceptors ${ }^{[22]}$. Due to the complex composition of oxidative processes, the antioxidant activity could not be evaluated only using one single method. FRAP and ABTS assay was used in this study. As shown in Table 2, the antioxidant activities of all dried samples were enhanced compared to the fresh ones. Chang et al. (2006) ${ }^{[21]}$ also showed similar results. Besides FD dried samples, significant increase of antioxidant activity of dried Goji was observed after SC pretreatment. The strongest ferrous iron chelating capacity (43.69 $\mu \mathrm{mol} \mathrm{TE} / \mathrm{g})$ and ABTS. ${ }^{+}$radical scavenging activity (57.55 $\mu \mathrm{mol} \mathrm{TE} / \mathrm{g}$ ) were found in FD-ICPDD-dried Goji. The fact that higher TPC were found in dried samples conducive to higher antioxidant activities compared to the fresh ones (Table 2). The FRAP values of FD-ICPDD-dried (SC) samples were $44.5 \%$ higher than the FDdried (SC) samples, respectively, which were in good agreement with the increase of TPC contents (25.3\%). Therefore, the ICPDD processing also can increase the antioxidant activity of dried Goji.

\section{Conclusions}

Nutritional and antioxidant properties of dried Goji were significantly affected by different pretreatments and drying conditions. Compared to DW-pretreated samples, the SC pretreatment was more favorable because its improvement in overall qualities of dried Goji 
no matter which drying method was used. In detail, the SC pretreatment products exhibited shorter drying time, higher TPC, LBP, TCC and antioxidant activity.

Under SC-pretreatment, the FD-ICPDD was a more beneficial drying method compared with the FD, HAD and HAD-ICPDD because of the highest retentions of TPC, LBP and antioxidant activities (FRAP and ABTS). For obtaining high-quality and valuable Gojiproducts, FD-ICPDD should be the best choice. But the increased manufacturing cost because of the FD pre-drying should also be taken into account. HAD-ICPDD could be another alternative technique when energy saving was more considered.

\section{References}

[1] Jeszka-Skowron, M.; Zgoła-Grześkowiak, A.; Stanisz, E. Potential health benefits and quality of dried fruits: goji fruits, cranberries and raisins. Food Chemistry, 2017, 221, 228-236.

[2] Potterat, O. Goji (Lycium barbarum \& L. chinense): phytochemistry, pharmacology and safety in the perspective of traditional uses and recent popularity. Planta Medica, 2010, 76, 7-19.

[3] Cuccurullo, G.; Giordano, L.; Albanese, D. Infrared thermography assisted control for apples microwave drying. Journal of Food Engineering, 2012, 112, 319-325.

[4] Zhao, Q.S.; Dong, B.T.; Chen, J.J.; Zhao, B.; Wang, X.D.; Wang, L.W. Effect of drying methods on physicochemical properties and antioxidant activities of wolfberry (Lycium Barbarum) polysaccharide. Carboshydrate Polymers, 2015, 127(AUG), 176181.

[5] Donno, D.; Mellano, M.G.; Raimondo, E. Influence of applied drying methods on phytochemical composition in fresh and dried goji fruits by HPLC fingerprint. European Food Research and Technology, 2016, 242, 1-14.

[6] Huang, L.L.; Zhang, M. Trends in development of dried vegetable products as snacks. Drying Technology, 2012, 30, 448-461.

[7] Lyu, J.; Yi, J.Y.; Bi, J.F. Impacts of explosion puffing drying combined with hot-air and freeze drying on the quality of papaya chips. International Journal of Food Engineering, 2017, 13.

[8] Chen, Q.Q.; Li, Z.L.; Bi, J.F. Effect of hybrid drying methods on physicochemical, nutritional and antioxidant properties of dried black mulberry. LWT - Food Science and Technology, 2017, 80, 178-184.

[9] Istrati, D.; Vizireanu, C.; Iordachescu, G. Physico-chemical characteristics and antioxidant activity of goji fruits jam and jelly during storage. Annals of the University Dunarea de Jos of Galati Fascicle VI - Food Technology, 2013, 37, 100-110.

[10] Knockaert, G.; Lemmens, L.; Van, B.S. Changes in $\beta$-carotene bioaccessibility and concentration during processing of carrot puree. Food Chemistry, 2012, 133, 60-67.

[11] Chan, E.; Lim, Y.Y.; Wong, S.K. Effects of different drying methods on the antioxidant properties of leaves and tea of ginger species. Food Chemistry, 2009, 113, 
166-172.

[12] Sun, L.J.; Zhang, J.B.; Lu, X.Y. Evaluation to the antioxidant activity of total flavonoids extract from persimmon (Diospyros kaki L.) leaves. Food and Chemical Toxicology, 2011, 49, 2689-2696.

[13] Wang, Y.T.; Liu, F.X.; Cao, X.M. Comparison of high hydrostatic pressure and high temperature short time processing on quality of purple sweet potato nectar. Innovative Food Science and Emerging Technologies, 2012, 16, 326-334.

[14] Jihyun, J.; Hana, J.; Saerom, L. Anti-oxidant, anti-proliferative and anti-inflammatory activities of the extracts from black raspberry fruits and wine. Food Chemistry, 2010, 123, 338-344.

[15] Dias, M.G.; Camões, M.F.; Oliveira, L. Carotenoid stability in fruits, vegetables and working standards - effect of storage temperature and time. Food Chemistry, 2014, 156, 37-41.

[16] Cui, Z.W.; Li, C.Y.; Song, C.F. Combined microwave-vacuum and freeze drying of carrot and apple chips. Drying Technology, 2008, 26, 1517-1523.

[17] Zhang, X.R.; Qi, C.H.; Cheng, J.P. Lycium barbarum polysaccharide LBPF4-OL may be a new Toll-like receptor 4/MD2-MAPK signaling pathway activator and inducer. International Immunopharmacology, 2014, 19, 132-141.

[18] Hayat, K.; Zhang, X.M.; Chen, H.Q. Liberation and separation of phenolic compounds from citrus mandarin peels by microwave heating and its effect on antioxidant activity. Separation and Purification Technology, 2010, 73, 371-376.

[19] Krapfenbauer, G.; Kinner, M.; Gössinger, M. Effect of thermal treatment on the quality of cloudy apple juice. Journal of Agricultural and Food Chemistry, 2006, 54, 5453-5460.

[20] Papoutsis, K.; Pristijono, P.; Golding, J.B. Effect of vacuum-drying, hot air-drying and freeze-drying on polyphenols and antioxidant capacity of lemon (citrus limon) pomace aqueous extracts. International Journal of Food Science and Technology, 2016, 52, 18.

[21] Chang, C. H.; Lin, H.Y.; Chang, C.Y. Comparisons on the antioxidant properties of fresh, freeze-dried and hot-air-dried tomatoes. Journal of Food Engineering, 2006, 77, 478-485.

[22] Shahidi, F.; Zhong, Y. Lipid oxidation and improving the oxidative stability. Chemical Society Reviews, 2010, 39, 4067.

[23] Cui, Z.W.; Li, C.Y.; Song, C.F. Combined microwave-vacuum and freeze drying of carrot and apple chips. Drying Technology, 2008, 26, 1517-1523. 